\title{
GREEN BUSINESS MODELS FOR AN ELECTRICAL SOLUTION IN BUILDINGS
}

\author{
SORAYA MOLINERO PEREZ \& CAMILLE AURIAULT \\ LGI, Paris, France
}

\begin{abstract}
READY (Resource Efficient cities implementing ADvanced smart citY solutions) is a European project that has started in December 2014. It aims at developing innovative solutions to reduce the needs for fossil fuels and increase the energy efficiency at building level in two demonstration sites: Aarhus, Denmark, and Växjö, Sweden. These innovative solutions include photovoltaic thermal (PVT) panels, second-life batteries, mobility solutions, heat pumps, and smart meters. The concept of Green Business Model tackles these innovative initiatives by proposing business models, which contribute to reducing energy, water consumption, and GHG emissions, while encouraging recycling, and promoting a sustainable consumption. This paper includes the description of the integrated system that delivers electricity at building level. In addition, it has been described the three business models selected in collaboration with the partners of the project. For each option, the content of the business model, the role of the stakeholders, and its interactions have been presented, taking into account the local conditions of the two cities studied.
\end{abstract}

Keywords: Green Business Models, energy efficiency, buildings, electric vehicles, photovoltaic thermal panels, cooperation models.

\section{INTRODUCTION}

Nowadays, because of climate change and strong environmental objectives, companies are encouraged to develop "greener" solutions. Regulation is getting stronger and stronger regarding the reduction of Greenhouse Gas (GHG) emissions, energy, water consumption or waste. Moreover, due to the economic crisis, and an increasing competition, companies must introduce new products or innovative services for customers and reduce their costs (energy, supplies, etc.). These customers are more and more concerned about the environment. Indeed, $77 \%$ of European citizens agree that environmental problems have a direct effect on their daily life. In particular, $28 \%$ would be ready to buy environmentally friendly products even if the costs are a bit higher [1]-[3].

However, several barriers slow down the development of greener solutions. Firstly, innovation is costly for companies and not necessarily easy to put into practice. This is the case of the significant costs entailed during the initial stages of development of new materials and technologies. In addition, in order to recycle products and components, specific infrastructures might be required, thereby involving important Capital Expenditures (CAPEX) [4], [5]. Finally, changing the way of doing business by offering services instead of just selling products is a challenge that involves innovative ways of thinking.

In 2010, the Danish Enterprise and Construction Authority's division for research and analysis gave a first definition of green business models: "models that support the development of products and services (systems) with environmental benefits, reduce resource use/waste and which are economically viable. These models have lower environmental impact than traditional business models" [6].

Compared to more standard business models, Green Business Models focus on strategies to reduce energy consumption, while creating environmental and economic benefits for the supplier and the customer. That is to say, all the changes that a company has to address in order to approach a more sustainable value chain or activity [4], [7], [8]. 
Finally, according to IDEA Consult in a report for the European Commission [9], a Green Business Model can be defined as "the use of innovative technological or non-technological solutions and or cooperation with other market actors, leading to increased economic or environmental efficiency, resulting in the achievement of a business model more 'decoupled' from environmental costs".

In this regard, the READY project highlights some of the innovation already taking place in European cities. It aims at developing and implementing innovative solutions to reduce the needs for fossil fuels and release of $\mathrm{CO}_{2}$ to nearly zero in $\mathrm{t}$ two demonstration sites. These innovative solutions include photovoltaic thermal panels, second-life batteries, mobility solutions, heat pumps, and smart meters.

\subsection{Methodology}

The methodology presented hereafter has been specifically developed to support the READY partners in the process of co-designing green business models. It is built on a review of business models in the building sector and has been extended by creative and visual tools used in business innovation. To illustrate this, we have drawn on the Value Proposition Design framework, originally developed by Osterwalder [10], and the Business environment tool, which has been applied to determine the interaction between stakeholders. The approach undertaken is divided into five steps, which are represented on Fig. 1:

Step 1: definition of green business models. This step is based on existing publications describing different definitions and tools to assist companies in their elaboration of a business model. The definition chosen is based on the state-of-the-art review and is adapted to the READY project by selecting specific dimensions of interest, such as key partnerships, customer segments, among others.

Step 2: understanding business models for individual technologies. It is important to understand the current situation of each stakeholder before integrating the technologies: main applications, targeted customers, costs, partnerships required, etc.

Step 3: Creation of green business models for the integrated solution. Based on previous steps, different business model options were elaborated by LGI for the integrated solution.

Step 4: Collaborative workshops with READY partners. Getting feedback from the partners was crucial to validate the business model options and determine whether they are feasible or not.

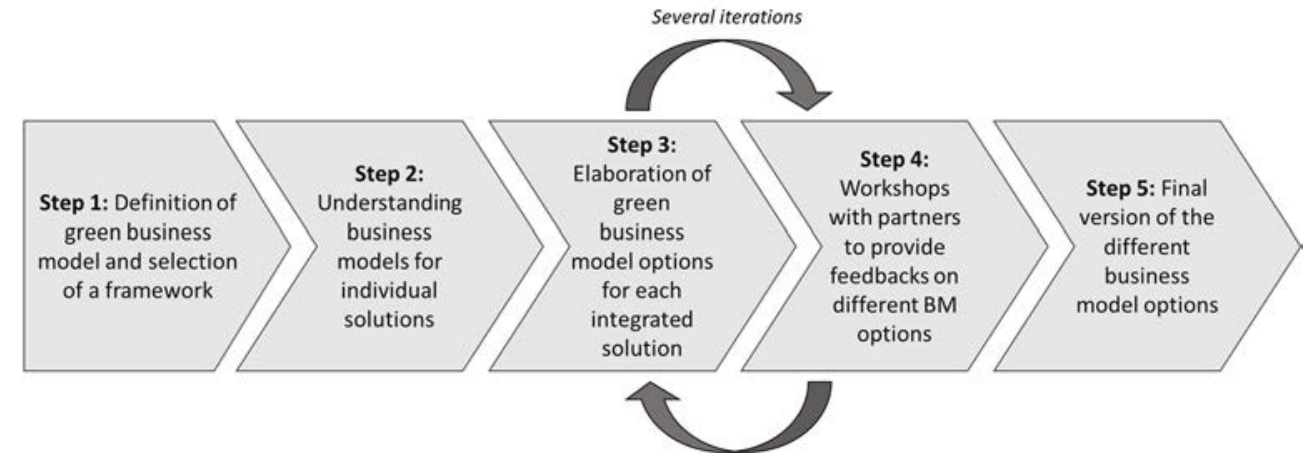

Figure 1: Steps of the methodology used in READY (LGI, 2016). 

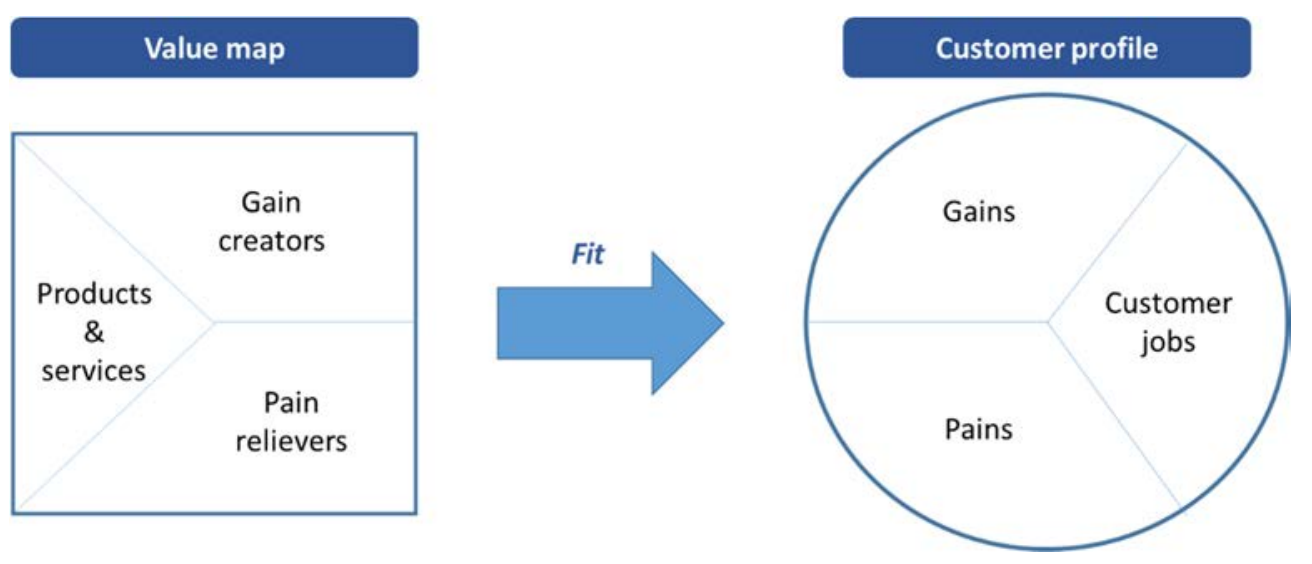

Figure 2: Value proposition canvas [10].

Several iterations with the partners have provided relevant recommendations to improve the business models presented.

Step 5: final version of the business model options. Based on comments provided by the READY partners, three final business model options were selected.

For the step 4, a workshop was organised in Aarhus between from $22^{\text {nd }}$ to $24^{\text {th }}$ August 2016 with the objective of validate and get feedback for the business models proposed. For this workshop, two different methodologies were used: The Value Proposition Design and the Business Environment.

The objective of the Value Proposition Design methodology is to better understand the type of customer to create new products or services. This methodology was explained in the book "Value Proposition Design" [10]. Within this methodology, a specific tool has been selected "the Value Proposition Canvas." It is composed by the customer profile for which participants of the workshop must identify customer's jobs, pains and gains. Firstly, customer's jobs describe what customers are trying to get done in their work as expressed in their own words. Secondly, pains describe bad outcomes, risks and obstacles related to customer jobs. And finally, gains describe the outcomes that customers want to achieve or the concrete benefits they are seeking. Once the customer profile is established, participants can propose additional services for the company on the value map.

The value map is composed of the following elements. The products and services section; a list on which a value proposition is built around a specific customer segment. Gain creators describe how your products and services create gains for customers [10]. Finally, pain relievers describe how your products and services alleviate customer's pains. Fig. 2 summarises the different sections of the value proposition canvas.

The second methodology used in the workshop was the Business Environment. The objective of this tool was to identify several business model options by representing the different stakeholders involved and the links or flows between them.

\section{THE INTEGRATED SYSTEM}

The integrated system deployed in READY produces, monitors and stores electricity at building level and it is represented on Fig. 3. It includes the following modules: 


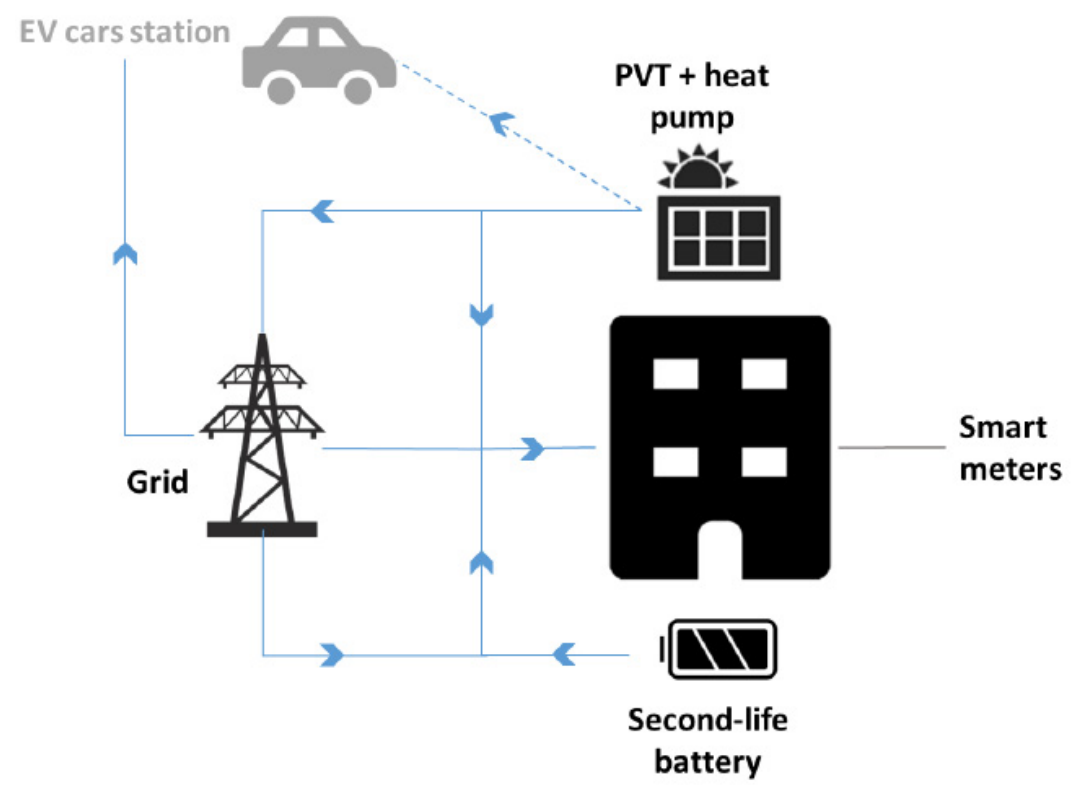

Figure 3: Integrated System: electricity at building level (LGI, 2017).

- Photovoltaic-thermal solar panels + heat pump: the PVT panels produce both heat and electricity while the heat pump cools the solar panel and increases the temperature of the heat produced by the PVT if necessary.

- Second-life batteries: they store the daily electricity produced by the PVT and the user does not have to consume it directly. The batteries have a capacity of $250 \mathrm{kWh}$.

- Smart meters: they monitor the electricity, heat, and water for an apartment.

- EV stations: they represent a potential extension of the system. They would be located close to multi-family buildings could be used an additional solution to store the electricity produced by the solar panels that cannot be used immediately.

\section{GREEN BUSINESS MODEL OPTIONS}

This section describes the three business model options that have been proposed for the integrated solution of the READY project. Each option describes role of the different stakeholders, its interactions (Business Environment), and the tasks they carry out eventually.

\subsection{Business model option 1: Selling equipment}

\subsubsection{Description}

In this model, the PVT manufacturer acts as an integrator and sells the integrated solution to the building owner. The PVT manufacturer buys the smart meters, the batteries and the management system and sells all the equipment to the building owner as one integrated solution. It is more likely that the integrator is the PVT manufacturer amongst the other manufacturers since batteries are used to store the energy produced by the PVT and smart meters must measure the electricity produced and used. The PVT panels are the most "independent" technology. The package is sold with a warranty for maintenance. The 
management system can be operated remotely. If there is any problem, the corresponding technical provider will fix the problem as part of the warranty of the package. For the installation and maintenance, the PVT manufacturer works in collaboration with the other manufacturers even if he remains the only contact point for the building owner.

Other manufacturers can sell their system to the PVT manufacturer. They assist the PVT manufacturer for the installation and maintenance of their equipment.

The building owner buys the integrated solution to the PVT manufacturer to increase the value of his building, decrease his electricity bill from the grid and improve his green image. The purchase of the integrated system represents a high upfront investment. To get reimbursed, the building owner can either increase rents or share the energy savings with the tenants. In addition, it can benefit from local or national grants or subsidies which reduce the cost of initial investment.

Municipalities provide financial support to convince building owners to start doing refurbishment work and implement renewable energy equipment.

Finally, utilities supply electricity to the building owner through an Energy Supply Contract (ESC). The utility buys the extra electricity not consumed by the building owner and sent to the grid.

\subsubsection{Business environment}

Fig. 4 represents the business environment of the first business model option - selling equipment.

\subsection{Business model option 2: Leasing equipment}

\subsubsection{Description}

In this model, the equipment is leased to the building owner so that he does not have to make any high upfront investment.

The PVT manufacturer buys the smart meters, the batteries and the management system and leases all the equipment to the building owner as one integrated solution. The package

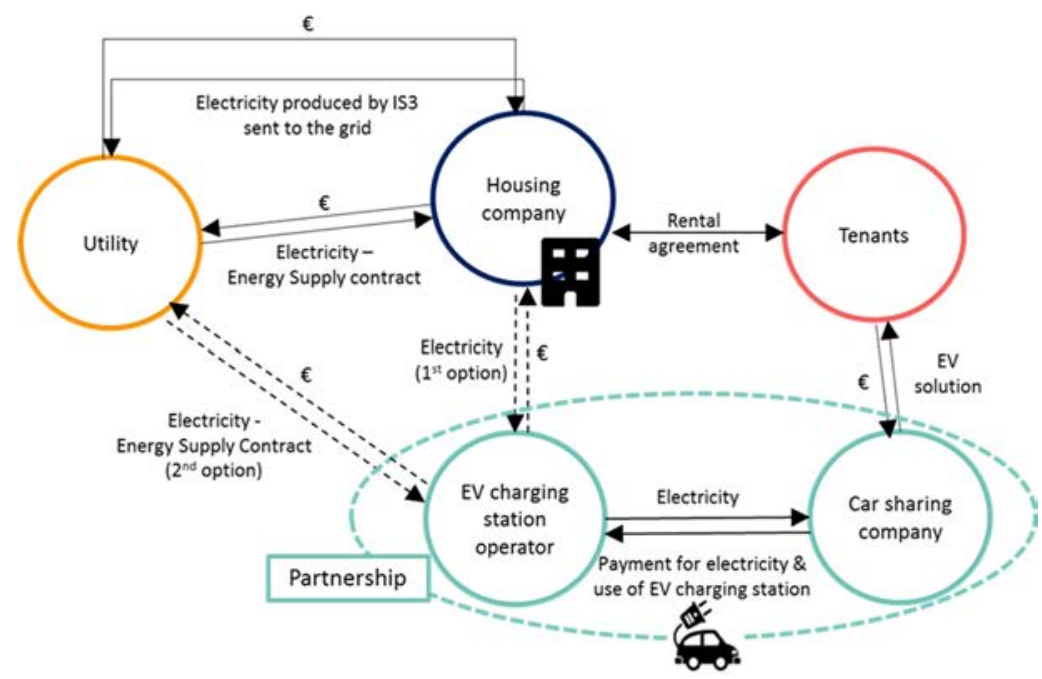

Figure 4: Business environment BM 1. 
offered includes installation, operation and maintenance (previously negotiated with other manufacturers). It gets reimbursed with the lease paid each month by the building owner. Since the PVT manufacturer does not have any direct payment, he must have strong working capital or be supported by a financial institution, such as a pension fund.

Manufacturers produce respectfully smart meters and battery and managements systems and sell them to the PVT manufacturer. They work in collaboration with the PVT manufacturer concerning the installation, operation and maintenance of the equipment.

The building owner pays a rent each month to use the equipment and thus consumes less electricity from the grid. However, tenants pay the electricity bill, so to get reimbursed, the building owner can either share the savings with the tenants or increase rents. At the end of the leasing, the building owner can buy the equipment at a reduced price.

Utilities provide the other share of electricity needed to the building owner according to an Energy Supply Contract (ESC). The utility buys the electricity produced and not consumed by the building owner.

A financial institution is required to support financially the integrator, e.g. the PVT manufacturer over its return-on-investment period. For a pension fund, renewable energy investments are interesting since they offer long-term predictable and stable cash-flows [11].

\subsubsection{Business environment}

The business environment for the second business model option - leasing equipment - is represented on Fig. 5.

\subsection{Business model option 3: Rent a roof and Power Purchase Agreement (PPA)}

\subsubsection{Description}

In the third option, the building owner receives an incentive such as a rent every month for the installation of PVT panels, batteries and smart meters. The rent brings an additional benefit to convince him to install the equipment. In exchange, the building owner, must buy all the electricity produced and stored through a Power Purchase Agreement (PPA) so that

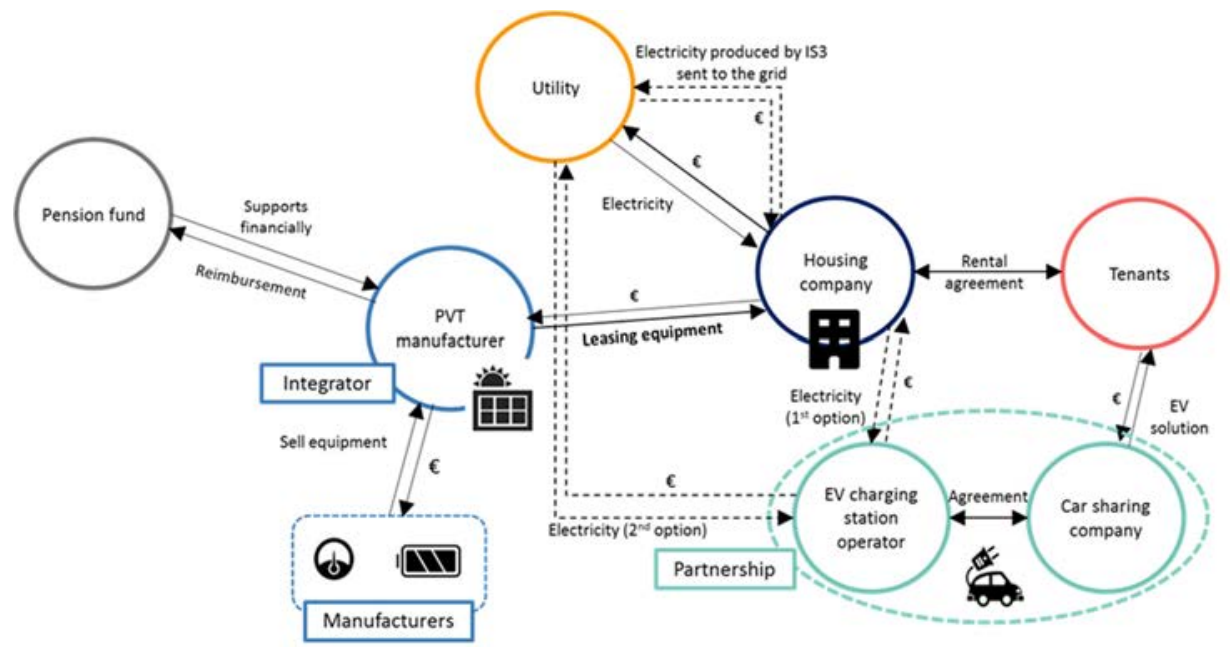

Figure 5: Business environment: BM 2. 
the business model is viable. To be an attractive option, the PPA can stipulate that the building owner buys electricity from the utility with a $10 \%$ discount compared to market price.

The equipment is sold under the format of a package: PVT panels, batteries and smart meters. A company must do the integration. However, in order to be able to give a rent to the building owner, the company commercialising the package must have important working capital and a trustful reputation. A local utility is then considered. Indeed, the utility has the funding required to implement this business model and already has a contact base. By proposing this solution, they would enter the market and thus prevent competition from other PV companies. The utility can provide the rent as a specific gain on the electricity bill of the building owner. To be economically viable, the utility must negotiate the price of equipment to the manufacturers to buy a large number of equipment at a lower price, benefiting from economies of scale. With these economies, the utility will be able to provide a rent to the building owner. Depending on the local conditions, the utility would also sell corresponding energy savings obligations to the energy market. In Denmark, this would not be possible since energy savings obligations only concern energy efficiency measures and not the production of renewable energy.

Manufacturers provide the equipment and sell it directly to the utility at a lower cost resulting from economies of scale. They are responsible for the manufacturing and the maintenance.

\subsubsection{Business environment}

The business environment for the third business model option - rent-a-roof and PPA - is represented on Fig. 6.

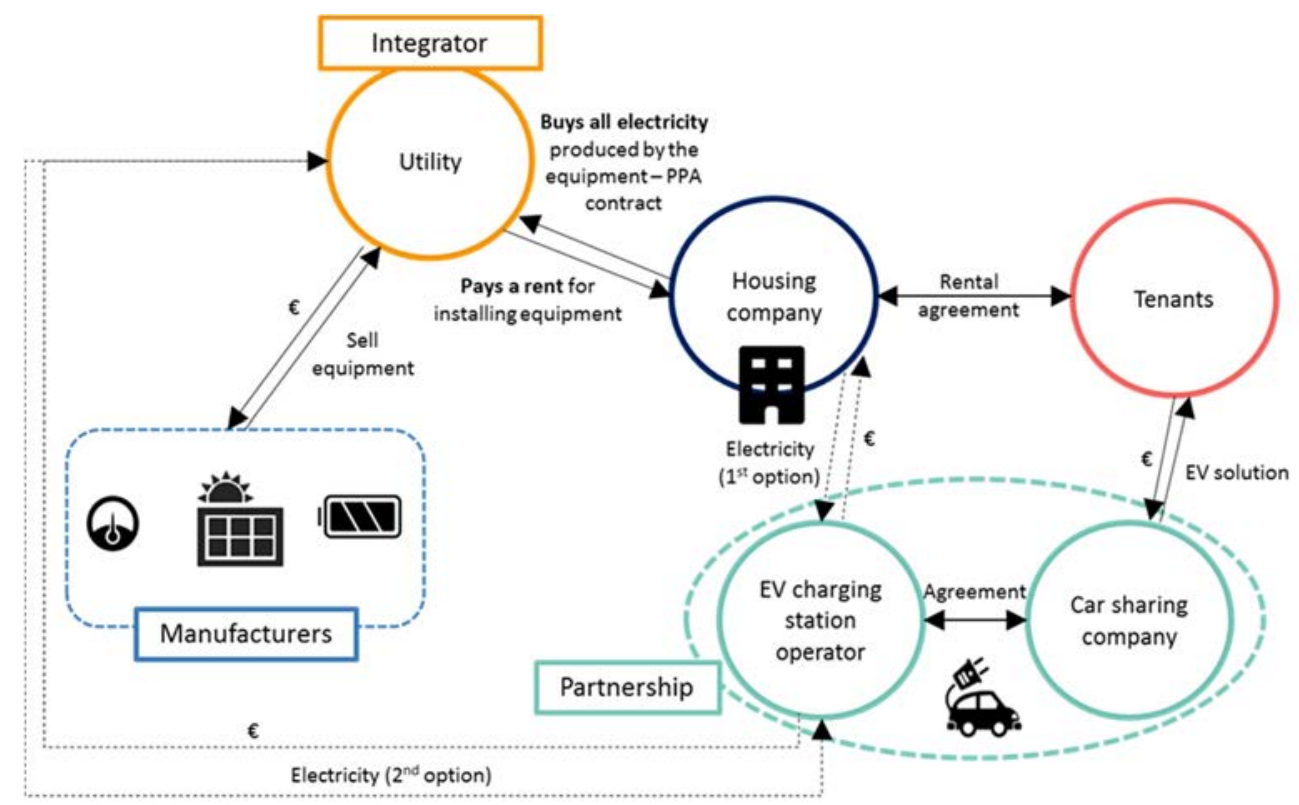

Figure 6: Business Model environment - BM 3. 


\section{CONCLUSION}

The integrated system developed READY, includes technologies that produce, monitor, and store electricity at building level. It is composed of PVT panels, second life batteries, which store electricity produced by PV panels and not directly used by the consumer, and smart meters that monitor the electricity consumption of the apartments. In addition, EV charging stations placed near the multi-family buildings store the electricity produced by the PVT panels that is not stored into the batteries.

The term Green Business Model refers to an economically viable model, which creates and delivers value to its customers while encouraging sustainability, a reduction of resource use and/or waste and promoting environmental benefits. The purpose of this paper is to describe the three most suitable green business model options, taking into account local constrains in Sweden and Denmark. Their market conditions and regulation were taken into account when elaborating the business model options.

A workshop with the technical partners took place in Aarhus in August 2016. The objective was to elaborate business models for the integrated solution. For each option, the role of the different stakeholders was detailed, the links between the stakeholders are represented on a schema called "business environment" and the advantages and disadvantages are gathered for the key stakeholders.

The next steps that will be taken within this project, head towards the replicability of the business model options proposed considering local conditions in other European cities. Policy and financial schemes that foster the replicability as well as the adaptation measures will be taken into account.

\section{ACKNOWLEDGEMENTS}

This project is funded by the European Commission. Grant agreement no: 609127. We would like to thank all the partners of READY whose contribution proved to be a milestone in the accomplishment of this part of the project.

\section{REFERENCES}

[1] European Commission. Attitudes of European Citizens towards the Environment.2014.

[2] Johnson, M.W., Reinventing your business model. Harvard Business Review, 86(12), pp. 50-59, 2008.

[3] Osterwalder, A. et al., Business model generation: A handbook for visionaries, game changers, and challengers, 2010.

[4] Morris, M.S., The entrepreneur's business model: Toward a unified perspective. Journal of Business Research, 58(6), pp. 726-735, 2005.

[5] Nordon, N.I., Green Business Model Innovation, 2012.

[6] For A. et al., (2010). Green Paper: Green business models in the Nordic Region: a key to promote sustainable growth.

[7] Chesbrough, $\mathrm{H}$. et al., The role of the business model in capturing value from innovation. Industrial and Corporate Change, 2002.

[8] Erwin Fielt, Q.U., Understanding business models vol. 3. Business Service Management Whitepaper. 2011.

[9] IDEA Consult. Exchange of good policy practices promoting Innovative/Green Business Models, (2013).

[10] Osterwalder, A. et al., Value Proposition Design. New Jersey: John Wiley \& Sons, 2014).

[11] Global Capital Finance. The European Renewable Energy Investor Landscape, 2014. 